\title{
Design and comparative analysis of three phase, four phase and six phase switched reluctance motor topologies for electrical vehicle propulsion
}

\author{
Sandeep Vuddanti ${ }^{1}$, Vinod Karknalli ${ }^{2}$, Surender Reddy Salkuti ${ }^{3}$ \\ ${ }^{1}$ Department of Electrical Engineering, National Institute of Technology Andhra Pradesh, India \\ ${ }^{2}$ Department of Electrical Engineering, Central University of Karnataka, India \\ ${ }^{3}$ Department of Railroad and Electrical Engineering, Woosong University, Daejeon, Republic of Korea
}

\section{Article Info}

Article history:

Received Sep 29, 2020

Revised Feb 17, 2021

Accepted May 3, 2021

\section{Keywords:}

Electric vehicles

Electrical machines

Finite element method

Machine modeling

Switched reluctance motor

\begin{abstract}
Switched reluctance motor (SRM) is attracting the scientific community in recent days because of its special structural benefits. Good research work has been conducted on this machine since the ages. It has evolved as an alternative to the conventional electrical machines in variable speed drives due to rugged architecture, high-speed operation, four quadrants, lack of magnet, and adaptability to harsh surroundings. This paper reviews different topologies of SRM for electric vehicle (EV) application and a comparative study of suitable machines for electric vehicle propulsion. This paper elaborates on the design methodology and the analysis of various phases of operation of SRMs. During the design procedure, the finite element method (FEM) of optimization is used to enhance motor performance. In this study, the three different phase $(3,4 \& 6)$ motors are analyzed in machine design software and finite element analysis outcomes and SRM simulation approach are discussed.
\end{abstract}

This is an open access article under the $\underline{C C B Y-S A}$ license.

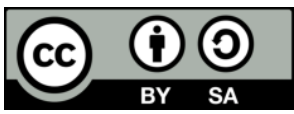

Corresponding Author:

Surender Reddy Salkuti

Department of Railroad and Electrical Engineering

Woosong University

17-2, Jayang-Dong, Dong-Gu, Daejeon 34606, Republic of Korea

Email: surender@wsu.ac.kr

\section{INTRODUCTION}

With the advantages of less carbon emission, high efficiency of fuel, and low noise, electric vehicles (EVs) are becoming increasingly popular in the transportation sector, as fossil fuel causes environmental pollution and also nowadays the world is on the edge of green technology [1], [2]. For different types of new energy vehicles, the motor drive system is the core and growing technology. Switched reluctance motor (SRM) is ideal for electric vehicle (EV) applications due to rugged architecture, high starting torque, wide range of speed, good overload performance, and inherent fault-tolerance performance [3]-[6]. In an EV, the electric motor plays a major role in terms of performance and output. This technology is commonly used in permanent magnet synchronous motors (PMSMs), induction motors, and brushless DC motors (BLDCs). The PMSM has a higher power density. However, the high cost of rare earth materials and limited supply has become a constraint for using BLDCs and PMSMs in EVs. Given the mass manufacturing of EVs in the future, it is important to look for a high-density and low-cost motor. This paper uses switched reluctance motor (SRM) which is emerging as a major contender for use in EV applications [7]-[10].

SRM works on the principle of reluctance torque. Both the rotor and stator have poles due to which it is also called a double salience machine. Windings are present only on the stator, as it doesn't contain any 
windings as well as a permanent magnet it makes it as a special electric machine when windings are excited by applying a source to the stator which makes the rotor align with the stator when the pole is exited [11]. Torque is developed by the continuous switching of stator windings which makes the machines more complex and required some focused studies. Compared to other electrical machines, SRMs have several advantages such as high temperatures loading capability, i.e., temperatures in the range of $160^{\circ} \mathrm{C}$ [12], It also has some difficulties, due to salient structure of SRM torque ripple is produced as well acoustic noise, which is a result of torque ripple as our application is electric machine noise doesn't cause any problem, torque ripples are to be minimized [13], [14].

Chaple [15] proposes the mathematical modeling of nonlinear SRM based on stator phase winding inductance. Real-time verification of an artificial neural network and adaptive neuro-fuzzy inference systembased rotor position estimation approaches for a 6/4 pole SRM drive system has been presented in Paramasivam [16]. Xudong [17] proposes the turn-off and turn-on angle on the torque ripple, effects of load torque, and electrical efficiency of switched reluctance drive are analyzed thoroughly based on the nonlinear dynamic model of SRM. An approach to reduce undesirable torque ripple in 6/4-pole 3-phase SRM by geometry modification and using control technique has been presented in [18]. A new speed-control approach for SRM drive based on a fast terminal sliding mode control technique is described in [19]. The dynamic model of 3 phase, high speed, SRM for EV applications is described in [20].

The finite element method-based optimization is performed on four phase 8/6 SRM using static and dynamic parameters in [21]. The design methodology of 8/6 SRM is carried out using Ansys Maxwell Software and analyzed the performance of motor for the converter control system is given in [22]. Systematic performance comparison of different outer rotor SRM configurations with help of a generalized design optimization framework is discussed in [23]. The power efficiency calculation of SRM using an indirect method based on electromagnetic torque is measured in [24]. A powertrain of a three-wheeler auto taxi in a series hybrid model is simulated for a city driving cycle is implemented in [25]. The Kim [26] presented the design of a compact and energy scroll compressor for SRM and its performance is validated for efficiency, torque, and noises. The design and analysis of finite element method-based switched reluctance motor for electric vehicle application is investigated in detail in [27]-[31]. The controller design for SRM motor drive with high efficiency is presented in [32]-[34].

The procedure for accurate modeling and sensorless estimation under all operating conditions in a nonlinear system is quite demanding. The popular solution is to formulate an SRM model based on data on flux linkages. There are two methods to collect these data: either by field analysis of the machine or experimental measurements. In most cases, SRM is modeled with the data produced by single-phase current unipolar excitation at different rotor locations. It is very common for two adjacent phases to be carried out concurrently, especially in high-speed applications where the current tails are important. For such instances, the SRM model fails. As a result, there are major errors in both the rotor orientation and the torque calculation. In the present paper, SRM undergoes a thorough finite element analysis (FEA) for various rotor positions, in which only one step is stimulated by different current rates. This paper elaborates the design methodology, sizing, machine modeling, and analysis of three-phase, four phase, and six phase switched reluctance motors. The SRM simulation approach used FEA and the results are discussed based on the following parameters; torque density, torque ripple, output power, and current.

\section{ANALYTICAL APPROACH AND MODELING}

Flux linkage of a coil $(\lambda)$ is directly proportional to the phase current (i) that runs through the coil and its phase inductance $(\mathrm{L})$, then,

$$
\begin{aligned}
& V=i R s+\frac{d \lambda}{d t}(\theta, i) \\
& \lambda=L(\theta, i) i
\end{aligned}
$$

where Rs is the phase resistance and $\theta$ is the rotor position.

Then it involves a partial derivative, where first, current (i) is considered as variable and inductance (L) as constant. As the inductance (L) is variable concerning rotor position and time, then replacing it in the above equation and solving, the voltage equation of one phase can be expressed [35],

$$
V=i R s+\frac{L(\theta, i) d i}{d t}+i \frac{d L}{d t}(\theta, i)
$$




$$
V=i R s+L(\theta, i) \frac{d i}{d t}+i \frac{d \theta}{d t} \frac{d L}{d \theta}(\theta, i)
$$

The derivative of rotor angular position $(\theta)$ in relation to time is motor angular speed $\left(\omega_{m}\right)$, then;

$$
V=i R s+L(\theta, i) \frac{d i}{d t}+i \omega_{m} \frac{d L}{d \theta}(\theta, i)
$$

The equations and circuit diagram describes SRM electrically, but for the complete modeling it is necessary to notice the machine mechanics. The per phase equivalent circuit of SRM has been depicted in Figure 1.

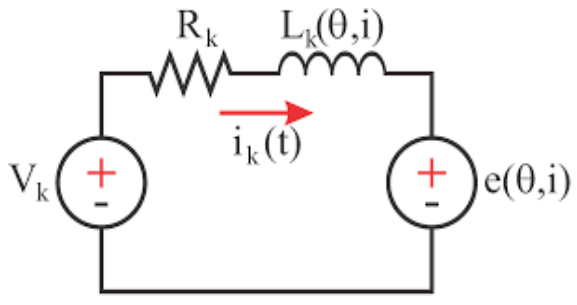

Figure 1. Per phase equivalent circuit of SRM

Torque equation can be derived by applying Faraday's law of electromagnetic induction, the electromotive force (emf) induced is given by [36],

$$
e=-d \varphi(i, \theta) / d t
$$

where $\varphi(i, \theta)$ is the flux linkage which is a function of rotor angle and current, then

$$
\frac{d \varphi(i, \theta)}{d t}=\frac{L d i}{d t}+\frac{i d l}{d \theta} \frac{d \theta}{d t} \frac{L d i}{d t}+\omega_{m} i \frac{d l}{d \theta}
$$

The amount of power $(P)$ developed is given by $(8)$,

$$
P=\frac{\text { Lidi }}{d t}+\omega_{m} i^{2} \frac{d l}{d t}
$$

The amount of energy stored in a magnetic field $\left(W_{e}\right)$ is given by $(9)$,

$$
W e=\frac{1}{2} L i^{2}
$$

Power due to variation in magnetic field is given by (10), (11),

$$
\begin{aligned}
& \frac{d w e}{d t}=\frac{1}{2} L 2 i \frac{d i}{d t}+\frac{1}{2} \frac{i^{2} d L}{d t} \\
& \frac{d W e}{d t}=L i \frac{d i}{d t}+\frac{\frac{1}{2} i^{2} d L}{d \theta} \omega_{m}
\end{aligned}
$$

where $P_{m}$ is difference between power received from supply and power due to change in the magnetic field, and it is given by (12)

$$
P_{m}=\frac{1}{2} \omega_{m} i^{2} \frac{d L}{d \theta}
$$

whereas the torque $(\mathrm{T})$ is given by $\left(P_{m} / \omega_{m}\right)$, therefore,

$$
T=\frac{1}{2} i^{2} \frac{d L}{d \theta}
$$




\section{DESIGN OF THREE PHASE, FOUR PHASE, AND SIX PHASE SRM TECHNOLOGIES}

The designing procedure of a machine follows a certain procedure like the selection of material, calculation of machine parameters are the prerequisites for machine modeling. After these mathematical calculations, the simulation process follows a certain algorithm and it is depicted in Figure 2. This figure shows the design procedure for designing the switched reluctance motor [37]. The designing steps for the construction of SRM are as follows:

- Step 1: Select the required number of phases, rotor, and stator poles.

- Step 2: Calculate machine parameters of SRM to find its average electromagnetic torque.

- Step 3: Select the magnetic material for the ferromagnetic core of SRM with the known values of the B-H curve.

- Step 4: Calculate static parameters by using FEM or by the theoretical method. The main static parameters are phase inductance, flux linkage, rotor position for the whole operation range, and electromagnetic torque versus phase current.

- Step 5: Input the measured static parameters into the SRM mathematical model, and examine the 'voltage', 'current', 'flux linkage', and 'torque' waveforms for varying loads and speeds within its operating range.

- Step 6: From the obtained waveforms, calculate the input power, output power, all types of losses, and efficiency.



Figure 2. Design methodology of SRM

\section{GEOMETRY DETAILS AND SIZING}

The design of SRM is a multidisciplinary aspect, which involves electromagnetic, mechanical, thermal, and acoustic design. Considering the industry's point of view, technological and cost aspects issues are also accounted for. The motor designing problem is to find out the material, geometry, and sets of topologies. The design aspect depends upon the specific application as weight, size, fault tolerance, low torque ripple content. The output equation relates to bore diameter, speed, length, electric and magnetic loadings for the output of the machine [38]. Generally, this machine design will be started from the output equation, therefore the power developed equation can be expressed as (14), 


$$
P_{d}=K_{e} K_{d} K_{1} K_{2} B A_{s} D^{2} L N_{r}
$$

where $K_{d}$ is the duty cycle, $K_{e}$ is efficiency, $K_{1}$ and $K_{2}$ are the constants, D is bore diameter, B is stator flux density at the aligned position, $N_{r}$ is rotor speed in revolution per minute, L is axial length, and $A_{s}$ is stator electrical loading (25000-90000 At/m). Then the $A_{s}$ is expressed as (15),

$$
A_{s}=\frac{2 T_{p h} * i * m}{\Pi D}
$$

where $T_{p h}$ is the turns per phase, $\mathrm{m}$ is the number of phases. The duty cycle is expressed as (16),

$$
K_{d}=\frac{{ }^{\theta_{i * q P r}}}{360}
$$

Initially, the duty cycle is assumed to one. Generally, at the rated operating point, the range of $K_{2}$ is expressed as (17),

$$
0.65<K_{2}<0.75
$$

The general range of specific electric loading in amp-conductors per meter is expressed as (18),

$$
25000<A_{s}<90000
$$

The selection of pole arcs is an important factor for SRM design. Two important things to be considered are shaping of static torque vs rotor position and self-starting requirement. It is desirable that the stator and rotor pole width should be the same or almost equal. Optimum pole widths must be selected by considering the aligned phase inductance, increased slot area, mechanical stiffness, and high inductance ratio, i.e.,

$$
\beta_{r} \geq \beta_{s}
$$

where $\beta_{s}$ and $\beta_{r}$ are stator pole arc and rotor pole arc respectively.

The selection of poles is preferred to have a ratio among rotor, and stator to be a non-integer even number based on the combinations of $6 / 4,8 / 6,12 / 8,12 / 10$ are followed [17]. The air gap is determined by the manufactures based on constraints imposed on them; small machines have air gaps ranging $(0.18-0.25) \mathrm{mm}$,

\begin{tabular}{|c|c|c|c|}
\hline & $3-\varphi$ & $4-\varphi$ & $6-\varphi$ \\
\hline Stator outer diameter $\left(D_{s}\right)$ & $190 \mathrm{~mm}$ & $190 \mathrm{~mm}$ & $190 \mathrm{~mm}$ \\
\hline Rotor diameter $\left(D_{r}\right)$ & $109.6 \mathrm{~mm}$ & $109.6 \mathrm{~mm}$ & $109.6 \mathrm{~mm}$ \\
\hline Stack length $(L)$ & $80 \mathrm{~mm}$ & $80 \mathrm{~mm}$ & $80 \mathrm{~mm}$ \\
\hline Air gap $(G)$ & 0.6 & 0.6 & 1 \\
\hline Stator pole $\left(N_{S}\right)$ & $6 \mathrm{~mm}$ & $8 \mathrm{~mm}$ & $12 \mathrm{~mm}$ \\
\hline Rotor pole $\left(N_{r}\right)$ & $4 \mathrm{~mm}$ & $6 \mathrm{~mm}$ & $8 \mathrm{~mm}$ \\
\hline No. of phase $(M)$ & 3 & 4 & 6 \\
\hline Stator pole arc $\left(\beta_{s}\right)$ & $21 \mathrm{~mm}$ & $21 \mathrm{~mm}$ & $21 \mathrm{~mm}$ \\
\hline Rotor pole arc $\left(\beta_{r}\right)$ & $23 \mathrm{~mm}$ & $23 \mathrm{~mm}$ & $23 \mathrm{~mm}$ \\
\hline Stator yoke thickness $\left(Y_{S}\right)$ & $14 \mathrm{~mm}$ & $14 \mathrm{~mm}$ & $14 \mathrm{~mm}$ \\
\hline Rotor yoke thickness $\left(Y_{r}\right)$ & 15 & 15 & 15 \\
\hline Shaft diameter $\left(D_{s h}\right)$ & 30 & 30 & 30 \\
\hline
\end{tabular}
and for servo applications, it is in the range of (1-3) $\mathrm{mm}$. The outer diameter can be derived from,

$$
D_{0}=D+2 b s y+2 h s
$$

Here $b s y$ and $h s$ refers to stator back iron thickness and stator pole thickness. The resulting dimensions of the topologies analyzed are present in Table 1 .

\section{FINITE ELEMENT METHOD ANALYSIS}

\subsection{Finite element method analysis of 3- $\varphi$ SRM}

Finite element analysis of SRM of 6/4 SRM has been carried out by energizing a single-phase SRM by applying current as input to the finite element method magnetics (FEMM), Altair Flux where the rotor is rotated at a certain angle for the analysis of the machine. The magnetic flux density of a machine can be observed and analyzed from the legend shown in Figure 3. 


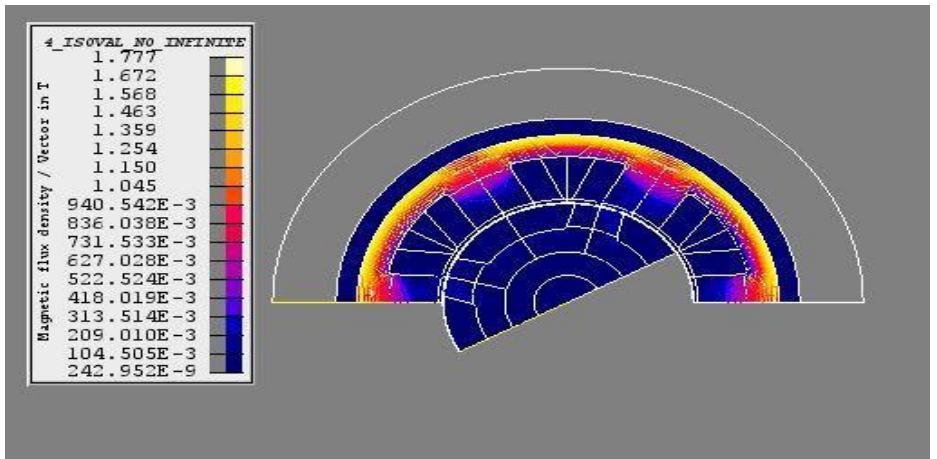

Figure 3. FEMM of 3- $\varphi$ SRM

\subsection{Finite element method analysis of 4- $\varphi$ SRM}

In this case (i.e., Finite element analysis of 6/4 SRM), stator and rotor numbers are changed along with the phase of coil conducting, and the coil of current-conducting is initiated to solve and the analysis of the machine is obtained. The FEMM of 4- $\varphi$ SRM has been depicted in Figure 4.

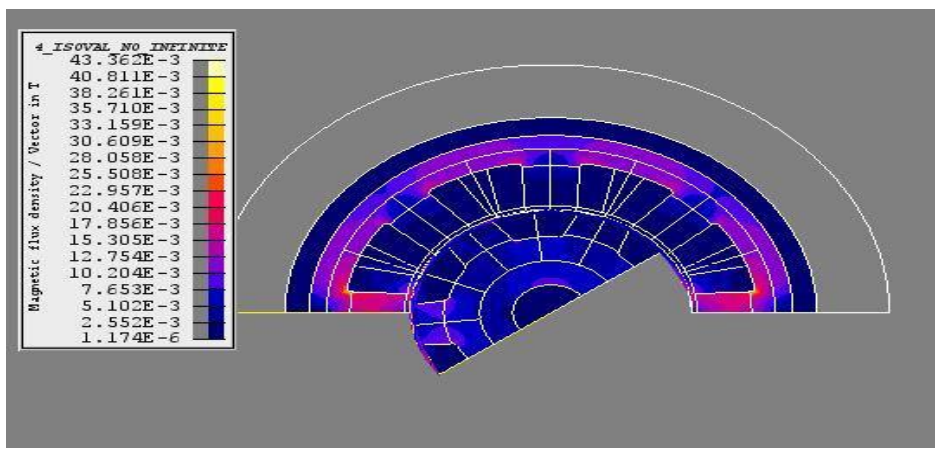

Figure 4. FEMM of 4- $\varphi$ SRM

\subsection{Finite element method analysis of 6- $\varphi$ SRM}

During the phase excitation condition, there will be the generation of mmf (magnetomotive force) which can be observed clearly in this analysis. Stator poles are excited by certain input that is the current through the coil conductors which resulting in the $\mathrm{mmf}$ at the edge of the poles. Figure 5 depicts the result of magnetic flux density of 6- $\varphi$ SRM. The analysis executes the magneto-motive force (mmf) to get flux paths and builds the magnetic equivalent circuit and helps to have the analytical models of saturable airgap with the suitable stator and rotor poles and nonlinear iron yoke.

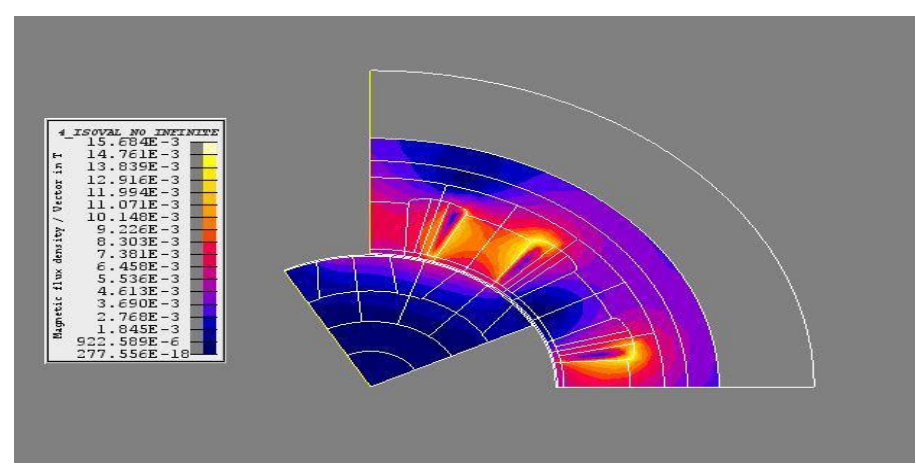

Figure 5. FEMM of 6- $\varphi$ SRM 


\section{SIMULATION RESULTS AND PERFORMANCE EVALUATION}

SRM design in the above section gives an idea to picturize the modeling of the machine, from the experiment conducted on SRM for various topologies. Torque output has been derived from all the designed modules as torque is the most important feature for an electric machine which is being used for mechanical works like traction. Torque per ampere of each machine is also observed in this work.

\subsection{Three-phase (6/4) SRM}

Here, the torque is observed by using the finite element analysis of 3- $\varphi$ SRM. Input is current and it varies from 0A to 20A. Each curve on the graph depicts the torque per ampere for varying angular rotation of the rotor in the range $\left(0-30^{\circ}\right)$. Figure 6 depicts the torque per ampere of 3 -phase (6/4) SRM. From this graph, it can be concluded that at an angle of $15^{\circ}$ it is increasing and entering the aligned position of the rotor to attain maximum torque and then it starts decreases at an angle of $22^{\circ}$.

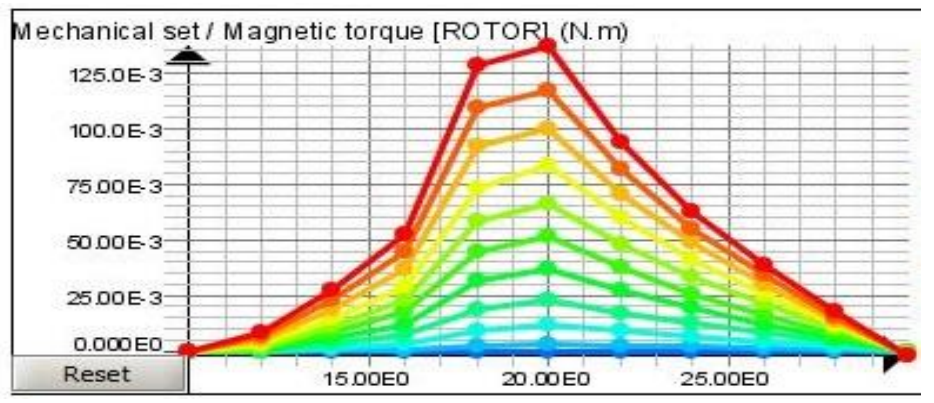

Figure 6. Torque per ampere of 3-phase (6/4) SRM

\subsection{Four phase (8/6) SRM}

As mentioned earlier, here also the torque is observed by using finite element analysis of 4- $\varphi$ SRM. Input is current and it varies from $0 \mathrm{~A}$ to $20 \mathrm{~A}$. Each curve on the graph (i.e., Figure 7) depicts the torque per ampere for varying angular rotation of the rotor from $0^{\circ}$ to $30^{\circ}$. From Figure 7 , it can be concluded that at an angle of $6^{\circ}$ it is increasing and entering the aligned position of the rotor to attain maximum torque and then it starts decreases at an angle of $27^{\circ}$.

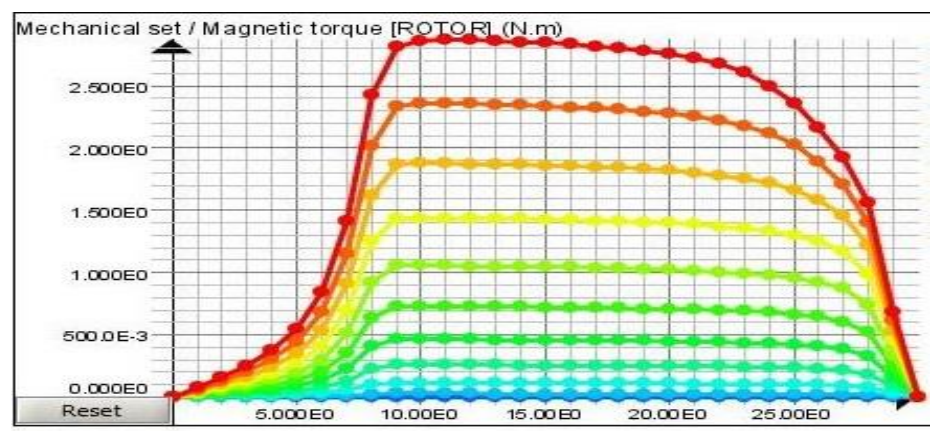

Figure 7. Torque per ampere of four phase (8/6) SRM

\subsection{Six phase (12/8) SRM}

The torque per ampere of six phase (12/8) SRM has been depicted in figure 8 . Here, the torque is observed by using the finite element analysis of 3- $\varphi$ SRM. Input is current varying from 0 A to $10 \mathrm{~A}$. Each curve on the graph depicts the torque per ampere for varying angular rotation of the rotor in the range of $\left(15^{\circ}-30^{\circ}\right)$. From this figure, it can be concluded that the torque density is less even though it produces instant torque with less or minor variation in torque with the varying current.

Table 2 presents the comparison of torque density, torque ripple, and output power of $3-\varphi, 4-\varphi$, and 6- $\varphi$ SRMs. Table 3 presents the comparison of SRM based on torque per unit ampere of 3- $\varphi, 4-\varphi$, and 6- $\varphi$ SRMs. All the torque per unit ampere values are presented in Table 3 and all of them are at the maximum point, i.e., in the aligned position.

Design and comparative analysis of three phase, four phase and six phase switched... (Sandeep Vuddanti) 


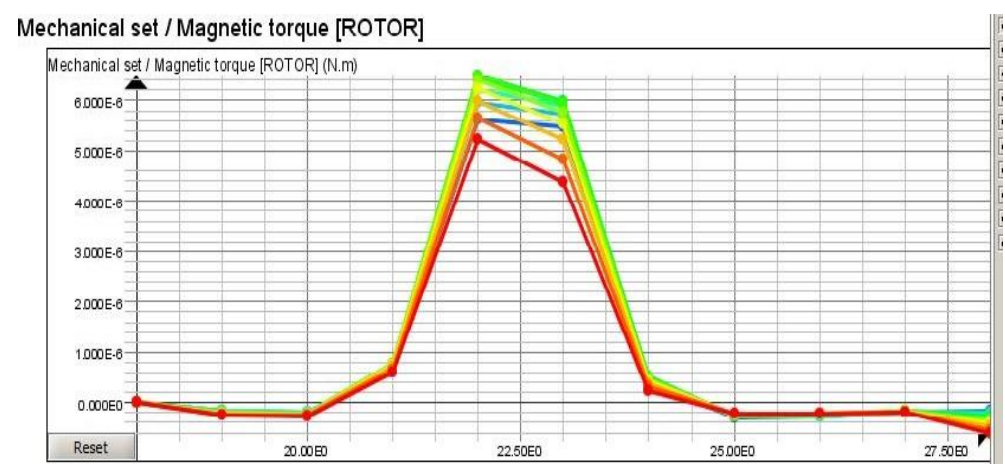

Figure 8. Torque per ampere of six phase (12/8) SRM

Table 2. Performance comparison of 3- $\varphi, 4-\varphi$, and 6- $\varphi$ SRM

\begin{tabular}{cccc}
\hline Parameters & $3-\varphi$ & $4-\varphi$ & $6-\varphi$ \\
\hline Torque density & Medium & High & Low \\
Torque Ripple & High & Medium & Low \\
Output power (T/A) & Medium & High & Low \\
\hline
\end{tabular}

Table 3. Comparison of SRM based on torque per unit ampere of 3- $\varphi, 4-\varphi$, and 6- $\varphi$ SRM

\begin{tabular}{cccc}
\hline Current & $3-\varphi$ Torque & $4-\varphi$ Torque & $6-\varphi$ Torque \\
\hline $2 \mathrm{~A}$ & $0.004 \mathrm{~N}-\mathrm{m}$ & $0.028 \mathrm{~N}-\mathrm{m}$ & $168.9 \mathrm{E}-7 \mathrm{~N}-\mathrm{m}$ \\
$4 \mathrm{~A}$ & $0.0172 \mathrm{~N}-\mathrm{m}$ & $0.11 \mathrm{~N}-\mathrm{m}$ & $675.7 \mathrm{E}-6 \mathrm{~N}-\mathrm{m}$ \\
$6 \mathrm{~A}$ & $0.0341 \mathrm{~N}-\mathrm{m}$ & $0.255 \mathrm{~N}-\mathrm{m}$ & $1.52 \mathrm{E}-6 \mathrm{~N}-\mathrm{m}$ \\
$8 \mathrm{~A}$ & $0.055 \mathrm{~N}-\mathrm{m}$ & $0.464 \mathrm{~N}-\mathrm{m}$ & $2.70 \mathrm{E}-6 \mathrm{~N}-\mathrm{m}$ \\
$10 \mathrm{~A}$ & $0.078 \mathrm{~N}-\mathrm{m}$ & $0.726 \mathrm{~N}-\mathrm{m}$ & $4.22 \mathrm{E}-6 \mathrm{~N}-\mathrm{m}$ \\
\hline
\end{tabular}

From the results of 6- $\varphi$ and 4- $\varphi$ SRM, 4- $\varphi$ machine is considered to be good among them from the observation of torque per ampere values of the machines [21]-[31]. However, these improvements are made at the cost of adding extra complexity to both the electric machine as well as power electronics system.

\section{CONCLUSION}

In this paper, an optimized design of (6/4) 3- $\varphi,(8 / 6) 4-\varphi$ and (12/8) 6- $\varphi$ switched reluctance motor (SRM) has been worked out providing the geometrical dimensions, the design procedure for electric vehicle propulsion has been proposed. The effect of these designs can be very useful and critical in selecting a proper SRM structure for a particular application like an EV application. According to conventional studies, SRM $8 / 6$ and 12/8 are the suitable configuration of machines for EV application. Considering the results of $6-\varphi$ and 4- $\varphi$ SRM, 4- $\varphi$ machine is considered to be good among them by the observation of torque per ampere values of the machines. However, these improvements are made at the cost of adding extra complexity to both the electric machine as well as power electronics system. Limitations are the controlling aspects as it consists of sensors it would be quite complicated to handle as designing was the main aspect of the proposed work it has given less importance controlling can be done through various readily available controllers PID controller would be a good option. Detailed controlled analysis and keeping the mechanical aspects like vibrations, acoustic and torque ripple reduction can be further worked and can be done in the optimization of the motor in hardware to test actual performance.

\section{ACKNOWLEDGEMENTS}

This research work was funded by “Woosong University’s Academic Research Funding - 2021”.

\section{REFERENCES}

[1] E. Bostanci, M. Moallem, A. Parsapour, B. Fahimi, "Opportunities and Challenges of Switched Reluctance Motor Drives for Electric Propulsion: A Comparative Study," IEEE Transactions on Transportation Electrification, vol. 3, no. 1, pp. 58-75, 2017, doi: 10.1109/TTE.2017.2649883.

[2] C. H. T. Lee, J. L. Kirtley, Jr. and M. Angle, "Switched Reluctance Motor Drives for Hybrid Electric Vehicles," Switched Reluctance Motor - Concept, Control and Applications, 2017, doi: 10.5772/intechopen.68911. 
[3] J. R. Riba, C.L. Torres, L. Romeral, A. Garcia, "Rare-earth-free propulsion motors for electric vehicles: A technology review," Renewable and Sustainable Energy Reviews, vol. 57, pp. 367-379, 2016, doi: 10.1016/j.rser.2015.12.121

[4] V. M. Kumar, K. V. Kumar, R. Saravanakumar, "Switched Reluctance Motor Converter Topologies: A Review," Innovations in Electrical and Electronics Engineering, vol. 626, pp. 55-63, 2020, doi: 10.1007/978-981-15-2256-7_6.

[5] M. Omekanda, "Switched reluctance machines for EV and HEV propulsion: State-of-the-art," 2013 IEEE Workshop on Electrical Machines Design, Control and Diagnosis (WEMDCD), Paris, France, 2013, pp. 70-74, doi: 10.1109/WEMDCD.2013.6525166.

[6] A., Pere, M. Torrent, B. Balduí, J. I. Perat, "Switched Reluctance Drives for Electric Vehicle Applications," Renewable Energy and Power Quality Journal, vol. 1, no. 1, pp. 311-317, 2005, doi: 10.24084/repqj01.373.

[7] A. Mohammad \& C. Rakan, "Realization of Hybrid-Electric Powertrain System for a Three Wheeler Auto Taxi," Bulletin of Electrical Engineering and Informatics (BEEI), vol. 1, no. 2, pp. 131-138, 2012, doi: 10.12928/eei.v1i2.243.

[8] H. Cheng, H. Chen, Q. Wang, S. Xu, S. Yang, "Design and control of switched reluctance motor drive for electric vehicles," 2016 14th International Conference on Control, Automation, Robotics and Vision (ICARCV), Phuket, 2016, pp. 1-6, doi: 10.1109/ICARCV.2016.7838783.

[9] K. M. Rahman, B. Fahimi, G. Suresh, A. V. Rajarathnam, M. Ehsani, "Advantages of switched reluctance motor applications to EV and HEV: design and control issues," IEEE Transactions on Industrial Applications, vol. 36, no. 1, pp. 111-121, 2000, doi: 10.1109/28.821805.

[10] H. Chen, J. J. Gu, "Implementation of the three-phase switched reluctance machine system for motors and generators," IEEE/ASME Transactions on Mechatronics, vol. 15, no. 3, pp. 421-432, 2010, doi: 10.1109/TMECH.2009.2027901.

[11] W. Wang, B. Fahimi, "Maximum torque per ampere control of switched reluctance motors," 2012 IEEE Energy Conversion Congress and Exposition (ECCE), Raleigh, NC, 2012, pp. 4307-4313, doi: 10.1109/ECCE.2012.6342236.

[12] J. D. Widmer, R. Martin, B. C. Mecrow, "Optimization of an 80-kW Segmental Rotor Switched Reluctance Machine for Automotive Traction," IEEE Transactions on Industry Applications, vol. 51, no. 4, pp. 2990-2999, 2015, doi: 10.1109/TIA.2015.2405051.

[13] Z. Fu, X. Wang, C. Cao, M. Liu, and K. Wang, "Research on Electromagnetic Force Distribution and Vibration Performance of A Novel 10/4 Switched Reluctance Motor," IOP Conference Series: Materials Science and Engineering, vol. 207, no. 1, pp. 1-9, 2017, Art. no. 012080, doi: 10.1088/1757-899X/207/1/012080.

[14] H. Yang, Y. Lim, H. Kim, "Acoustic Noise/Vibration Reduction of a Single- Phase SRM Using Skewed Stator and Rotor," IEEE Transactions on Industrial Electronics, vol. 60, no. 10, pp. 4292-4300, 2013, doi: 10.1109/TIE.2012.2217715.

[15] M. Chaple, S. B. Bodkhe, "The simulation and mathematical modeling of switched reluctance motor based on phase winding inductance," 2017 International Conference on Energy, Communication, Data Analytics and Soft Computing (ICECDS), Chennai, 2017, pp. 3048-3052, doi: 10.1109/ICECDS.2017.8390015.

[16] S. Paramasivam, S. Vijayan, M. Vasudevan, R. Arumugam, R. Krishnan, "Real-time verification of AI based rotor position estimation techniques for a 6/4 pole switched reluctance motor drive," IEEE Transactions on Magnetics, vol. 43, no. 7, pp. 3209-3222, 2007, doi: 10.1109/TMAG.2006.888811

[17] G. Xudong, R. Na, J. Chengyu, W. Xudong, Z. Yongqin, "Multi-objective optimization of switched reluctance motor drive in electric vehicles," Computers and Electrical Engineering, vol. 70, pp. 914-930, 2018, doi: 10.1016/j.compeleceng.2017.12.016.

[18] D. Marcsa, M. Kuczmann, "Design and control for torque ripple reduction of a 3-phase switched reluctance motor," Computers and Mathematics with Applications, vol. 74, no. 1, pp. 89-95, 2017, doi: 10.1016/j.camwa.2017.01.001.

[19] M. Divandari, B. Rezaie, A.R. Noei, "Speed control of switched reluctance motor via fuzzy fast terminal slidingmode control," Computers and Electrical Engineering, vol. 80, 2019, Art. no. 106472, doi: 10.1016/j.compeleceng.2019.106472.

[20] S. Kocan, P. Rafajdus, "Dynamic model of High Speed Switched Reluctance Motor for automotive applications," Transportation Research Procedia, vol. 40, pp. 302-309, 2019, doi: 10.1016/j.trpro.2019.07.045.

[21] P. Rafajdus, A. Peniak, D. Peter, P. Makys, L. Szabo, "Optimization of switched reluctance motor design procedure for electrical vehicles," 2014 International Conference on Optimization of Electrical and Electronic Equipment (OPTIM), Bran, 2014, pp. 397-404, doi: 10.1109/OPTIM.2014.6851033.

[22] S. R. Patel, N. Gandhi, N. Chaithanya, B. N. Chaudhari, A. Nirgude, "Design and development of switched reluctance motors for electric vehicle application," 2016 IEEE International Conference on Power Electronics, Drives and Energy Systems (PEDES), Trivandrum, 2016, pp. 1-6, doi: 10.1109/PEDES.2016.7914356.

[23] V. Rallabandi, P. Han, J. Wu, A. M. Cramer, D. M. Ionel and P. Zhou, "Design Optimization and Comparison of Direct-Drive Outer-Rotor SRMs Based on Fast Current Profile Estimation and Transient FEA," IEEE Transactions on Industry Applications, vol. 57, no. 1, pp. 236-245, 2021, doi: 10.1109/TIA.2020.3029995.

[24] M. Z. Qawaqzeh, V. Prus, A. Kalinichenk, M. Zagirnyak, "Determination of power parameters of switched reluctance motor based on instantaneous values of phase voltages and currents" Przegląd Elektrotechniczny, vol. 1, no. 12, pp. 103-106, 2016, doi: 10.15199/48.2016.12.26.

[25] M. Alam, R. Chabaan, "Realization of Hybrid-Electric Powertrain System for a Three Wheeler Auto Taxi," Bulletin of Electrical Engineering and Informatics (BEEI), vol. 1, no. 2, pp. 131-138, 2012, doi: 10.11591/eei.v1i2.243. 
[26] J. Kim, Y. Jeong, Y. H. Jeon, J. H. Kang, S. Lee, J. Y. Park, "Development of a switched reluctance motor-based electric compressor drive for HEVs/EVs applications," 2013 International Conference on Electrical Machines and Systems (ICEMS), Busan, Korea (South), 2013, pp. 622-629, doi: 10.1109/ICEMS.2013.6754515.

[27] Ş. İbrahim, P. Abdullah, E. Lale, "Design and analysis of switched reluctance motors," 2013 8th International Conference on Electrical and Electronics Engineering (ELECO), pp. 586-590, 2013, doi: 10.1109/ELECO.2013.6713902

[28] S. Sezen, E. Karakas, K. Yilmaz, M. Ayaz, "Finite element modeling and control of a high-power SRM for hybrid electric vehicle," Simulation Modelling Practice and Theory, vol. 62, pp. 49-67, 2016, doi: 10.1016/j.simpat.2016.01.006

[29] K. A. Karim, N. Abdullah, M. N. Othman, A. Jidin, R. N. Firdaus, "Modeling of 6 to 4 Switched Reluctance Motor using Coefficient Method and Analytical Method," Indonesian Journal of Electrical Engineering and Computer Science (IJEECS), vol. 7, no. 2, pp. 373-380, 2017, doi: 10.11591/ijeecs.v7.i2.pp373-380

[30] S. Narasimha, S. R. Salkuti, "Dynamic and Hybrid Phase Shift Controller for Dual Active Bridge Converter," International Journal of Engineering \& Technology, vol. 7, no. 4, pp. 4795-4800, 2018, doi: 10.14419/ijet.v7i4.24019.

[31] S. Narasimha, S. R. Salkuti, "An improved closed loop hybrid phase shift controller for dual active bridge converter," International Journal of Electrical and Computer Engineering (IJECE), vol. 10, no. 2, pp. 1169-1178, 2020, doi: 10.11591/ijece.v10i2.pp1169-1178

[32] S. Takanori, I. Shinya, T. Naoki, C. Akira, F. Tadashi \& N. Hironori, "Development of High Efficiency Switched Reluctance Motor," IEEJ Transactions on Industry Applications, vol. 126, no. 4, pp. 511-518, 2006, doi: 10.1541/ieejias. 126.511

[33] M. R. Besm,i "Geometry Design of Switched Reluctance Motor to Reduce the Torque Ripple by Finite Element Method and Sensitive Analysis," Journal of Electric Power and Energy Conversion Systems (JEPECS), vol. 1, no. 1 , pp. 23-31, 2016, doi: 10.25103/jestr.122.11

[34] N. K. Saxena, S. Gebrehiwot, D. Mena, "Controller Design for Electric Motor Derived Vehicle," Indonesian Journal of Electrical Engineering and Informatics (IJEEI), vol. 6, no. 2, pp. 125-131, Jun. 2018, doi: 10.11591/ijeei.v6i2.282.

[35] S. Narasimha, S. R. Salkuti, "Design and implementation of smart uninterruptable power supply using battery storage and photovoltaic arrays," International Journal of Engineering \& Technology, vol. 7, no. 3, pp. 960-965, 2018, doi: 10.14419/ijet.v7i3.12305.

[36] S. Narasimha, S. R. Salkuti, "Design and operation of closed-loop triple-deck buck-boost converter with high gain soft switching," International Journal of Power Electronics and Drive System (IJPEDS), vol. 11, no. 1, pp. 523529,. 2020, doi: 10.11591/ijpeds.v11.i1.pp523-529.

[37] C. Gan, J. Wu, Q. Sun, W. Kong, H. Li and Y. Hu, "A Review on Machine Topologies and Control Techniques for Low-Noise Switched Reluctance Motors in Electric Vehicle Applications," IEEE Access, vol. 6, pp. 31430-31443, 2018, doi: 10.1109/ACCESS.2018.2837111.

[38] K. Ashok, K. M. \& M. Vijay, "Closed-loop speed control of switched reluctance motor drive fed from novel converter with reduced number of switches," International Journal of Power Electronics and Drive Systems (IJPEDS), vol. 11, no. 1, pp. 189-199, 2020, doi: 10.11591/ijpeds.v11.i1.pp189-199. 